\title{
A GESTÃO DO TRABALHO DO ASSISTENTE SOCIAL NA POLÍTICA DE EDUCAÇÃO
}

\author{
SOCIAL ASSISTANT WORK MANAGEMENT IN EDUCATION POLICY \\ POLIITICA DE GESTIÓN DEL TRABAJO DEL ASISTENTE SOCIAL EN EDUCACIÓN
}

\section{Jaqueline Carvalho Quadrado}

Doutora em Sociologia pela Universidade de Brasília (UnB). Professora Adjunta na Universidade Federal do Pampa (UNIPAMPA).

jaquelinequadrado@unipampa.edu.br.

0000-0002-5220-3710

\section{Eduardo Lima}

Graduando em Serviço Social, Universidade Federal do Pampa (UNIPAMPA). elima2929@gmail.com.

\section{0-0002-6356-5100}

Correspondência: Universidade Federal do Pampa, CURSO DE SERVICCO SOCIAL. RUA ALBERTO BENEVENUTO, 3200 PASSO. 97670000 - São Borja, RS - Brasil

Recebido em: 12.10 .2020$.

Aceito em: 20.11.2020

Publicado em: 01.01.2021.

\section{RESUMO:}

O estudo objetivou compreender a importância do processo de gestão do trabalho do Assistente Social na Política de Educação, mais especificamente na Coordenação de Curso de Serviço Social. Questionou-se, se os princípios teóricos e metodológicos da gestão se aplicam no setor público federal, onde o trabalho a ser realizado já obedece a uma agenda previamente planejada e orquestrada pela esfera federal, por obedecer a planos e metas estabelecidas pelos órgãos gestores das políticas públicas. Em seguida, foi questionado, se seria possível construir o processo teórico-prático da gestão e como efetivá-lo no campo de atuação profissional, onde a supervalorização do trabalho burocrático interfere diretamente na ação profissional, processo esse que contribui para a construção de uma prática profissional esvaziada e acrítica. Ainda nesta diretriz de questionamentos, também se perguntou, quais os princípios teóricos e práticos da gestão que o assistente social poderia se apropriar enquanto instrumento de trabalho em sua atuação no setor público, onde o profissional, esbarra rotineiramente nos limites institucionais e nas relações de poder estabelecidas no aparelho estatal. $\mathrm{O}$ estudo documental e bibliográfico caracterizou-se por seu caráter exploratório e abordagem qualitativa. Considerou-se que o processo de valorização do trabalho burocrático vem gradativamente estimulando a burocratização da prática e o vazio profissional, fato que condiciona o exercício profissional ao tarefismo burocrático e rotineiro. A gestão do trabalho e a capacidade de planejar e organizar propositivamente a ação profissional tornam-se instrumentos de grande importância na formulação de propostas de enfrentamento aos desafios postos ao profissional de Serviço Social.

PALAVRAS-CHAVES: Comunicação; Ciência; Educação Superior; Propaganda; Publicidade Governamental.

\section{Introdução}

O estudo objetiva compreender a importância do processo de gestão do trabalho do Assistente Social na Política de Educação, no Curso de Serviço Social, do campus São Borja, da Universidade Federal do Pampa (Unipampa), enquanto ambiente de atuação profissional, com vistas a reconhecer este, como meio de possibilidades de universalização de direitos, através de uma perspectiva de gestão democrática. O texto materializa-se após uma série de questionamentos teóricos e práticos relacionados à coordenação do trabalho do assistente social e sua aplicabilidade no setor público, mais especificamente na esfera federal da Política de Educação. 
Neste sentido, questionou-se, se os princípios teóricos e metodológicos da coordenação se aplicam no setor público federal, onde o trabalho a ser realizado já obedece a uma agenda previamente planejada e orquestrada pela esfera federal, por obedecer a planos e metas estabelecidas pelos órgãos gestores das políticas públicas. Em seguida foi questionado, "se seria possível construir o processo teórico-prático da gestão" e "como efetivá-lo no campo de atuação profissional", onde há supervalorização do trabalho burocrático interfere diretamente na ação profissional, processo esse que contribui para a construção de uma prática profissional esvaziada e acrítica.

Esse processo de valorização do trabalho burocrático vem gradativamente "estimulando a burocratização da prática e o vazio profissional" (IAMAMOTO, 2003, p. 161), fato que condiciona o exercício profissional ao tarefismo burocrático e rotineiro. Ainda nesta diretriz de questionamentos, também se perguntou, "quais os princípios teóricos e práticos da gestão, que o assistente social poderia se apropriar enquanto instrumento de trabalho em sua atuação no setor público", onde o profissional, rotineiramente esbarra nos limites institucionais e nas relações de poder estabelecidas no aparelho estatal.

A proposta de estudo partiu da conjectura que a categoria ainda apresenta relativa resistência em reconhecer a gestão como instrumento de trabalho e de domínio do assistente social. A não apropriação de determinados princípios da gestão parte do desconhecimento que a categoria ainda apresenta sobre a temática em questão. Contudo, a partir da revisão das Diretrizes Curriculares da formação acadêmica em 1996, o currículo mínimo dos cursos de Serviço Social no Brasil, passou a contar com a gestão, como importante disciplina no conjunto da organização curricular que, também é entendida como instrumento de trabalho e de domínio do assistente social no seu exercício profissional.

Este trabalho foi realizado através de estudo documental e bibliográfico. Sendo que, o estudo documental consistiu em abranger documentos, principalmente, os institucionais, que contribuíram para o desenvolvimento do tema deste estudo. A pesquisa bibliográfica caracterizou-se por seu caráter exploratório e abordagem qualitativa, objetivando assim evidenciar os fundamentos da gestão que devidamente apropriados, contribuem para a realização do trabalho profissional na esfera da Política de Educação.

\section{Gestão e trabalho profissional: planejamento e ação profissional}

$\mathrm{Na}$ trajetória histórica da profissão, os assistentes sociais dedicaram-se à implementação das políticas pública sociais, mantendo assim, uma intrínseca relação 
com o Estado e suas demandas. Considerando que desde o surgimento da profissão, o Serviço Social esteve presente nas diversas áreas de intervenção estatal, como mediador e executor das políticas sociais, desenvolvidas e implementadas como estratégia de enfrentamento e principalmente de controle as desigualdades sociais. No âmbito governamental, o profissional sempre foi chamado a intervir junto às manifestações da questão social, nas áreas da saúde, educação, assistência, habitação entre outras.

Neste debate pontua-se brevemente como foram as primeiras aproximações do Serviço Social com a gestão. De acordo com estudiosos (NOGUEIRA 2007, FILHO; OLIVEIRA, 2012) o campo da administração, das organizações e da gestão começa a ganhar certa visibilidade no Serviço Social a partir da década de 1980, com os movimentos de reconceituação e ruptura pelo qual a profissão estava passando.

Rosa (2008) diz que a atuação do Serviço Social na gestão tem seus primeiros registros no estudo do Serviço Social de empresa, campo de trabalho que foi firmandose de forma gradativa e não somente no Brasil, mas nos demais países da América Latina, dos Estados Unidos e na Europa.

É notório que a Administração e o Serviço Social são dois campos de objetos distintos, pois o Serviço Social tem como seu objeto a questão social e suas múltiplas expressões e a Administração, ou gestão, define-se como [...] modo racional e calculado de ordenar os meios para atingir resultados (NOGUEIRA, 2007, p. 30). O autor ainda aponta

[...] o fundamento da gestão ou da administração é a noção de racionalidade, isto é, o uso da inteligência, da razão, para encontrar os meios mais adequados com vista à realização de resultados. Estes são definidos como objetivos a alcançar, ao passo que os meios dizem respeito às pessoas, aos modos e aos recursos que garantem a conquista dos objetivos (NOGUEIRA, 2007, p. 31).

Isso pode significar um problema para os assistentes sociais, mas para o pensamento administrativo é uma virtude, pois [...] idealmente, burocracia é administração profissional que visa, por meio da racionalização e do controle do trabalho, a eficiência e maximização de resultados (NOGUEIRA, 2007, p. 78). Desse modo, os gestores deverão ser lideranças capazes de atuar na gestão pública como agentes potencializadores na adesão do projeto democrático de sociedade e de gestão que se pretende [...] o gestor público deve ter competência teórico-metodológica, éticopolítica e técnico-operacional tanto para analisar os movimentos da economia, da política, da sociedade e de seus grupos e indivíduos (FILHO, 2013, p. 225). 
O argumento de Filho (2013) é bem elucidativo, quando diz que a proposta aos profissionais assistentes sociais que atuam na gestão pública é assumir a categoria "administração pública democrática", ou seja, aquela que tem como finalidade a equidade, a justiça social, a participação política, accountability e democracia "numa orientação de universalização e aprofundamento dos direitos" (FILHO, 2013, p. 220). Para este autor, esta concepção é que irá distinguir uma proposição democrática da gestão pública de uma abordagem meramente tecnicista ou centrada no mercado.

Nogueira (1998) contribui, do ponto de vista da gestão e de seus operadores. Para a autor, o essencial numa proposta de construção contra hegemônica ao neoliberalismo não está na apreensão de tecnologias gerenciais, mas sim na qualificação das pessoas para atuar na fronteira entre a técnica e a política. De modo que, o desenvolvimento de competências técnicas e habilidades gerenciais voltadas à realização do trabalho profissional na esfera da gestão pública da política de educação contribuem para substituição do agente subalterno e executivo por um profissional competente e qualificado para as novas funções requisitadas ao assistente social.

Inegavelmente, a contribuição mais proeminente sobre planejamento para o Serviço Social é da autora Myrian Veras Baptista (1978). O planejamento é concebido por Baptista (1978) como processo de aproximação com uma determinada realidade através de uma sistemática apoiada em conceitos técnicos- operativos e científicos ${ }^{2}$. A autora enfatiza que ele deve ser realizado num ciclo contínuo de "reflexão-decisão-açãoreflexão", configurando assim um processo dinâmico, não linear.

Baptista (1978, p. 14) esclarece a conceituação de cada uma dessas operações. A operação de reflexão "diz respeito ao conhecimento de dados, à análise e estudo de alternativas, à adaptação e combinação de conceitos e técnicas de diversas disciplinas relacionadas com a quantificação dos fatos sociais". A operação de decisão "se refere à escolha de alternativas, à determinação de meios, à definição de prazos". A operação da ação relaciona-se "a execução das decisões. É o foco central do planejamento". Por fim, a operação de revisão consiste numa "operação de crítica dos efeitos da ação planejada, com vistas ao embasamento de ações posteriores". O movimento de "reflexão-decisãoação-reflexão" assumido na decisão de planejar é caracterizado, de acordo com Baptista, pelas seguintes aproximações:

"construção/reconstrução do objeto; estudo de situação; definição de

\footnotetext{
${ }^{1}$ Termo sem tradução exata para o português, que remete à obrigação de membros de um órgão administrativo ou representativo de prestar contas a instâncias controladoras ou a seus representados (FILHO, 2013).

2 De acordo com Baptista (1979), o planejamento se realiza através de um processo de aproximações sucessivas, que tem como centro de interesse a situação definida como objeto de intervenção.
} 
objetivos para ação; formulação e escolha de alternativas; montagem de planos, programas e/ou projetos; implementação; controle da execução; avaliação do processo e da ação executada; retomada do processo em um novo patamar (BAPTISTA, 2003, p. 28)".

Outro autor que contribui de forma crítica sobre planejamento é Pedro Demo (1988), para ele o planejamento enquanto instrumento empregado pelo Estado, historicamente, tem forte propensão tecnocrática, sistêmica e impositiva. Esta propensão tecnocrática é marcada pelo "poder do técnico" que influencia "fluxos e recursos, construção de planos e programas, formas de avaliação e acompanhamento, em nome de um Estado, que pode ser mais ou menos autoritário" (DEMO, 1998, p. 42). Em outras palavras, o planejamento é restrito aos interesses de um grupo particularizado, o dos tecnocratas. Há uma clara distinção entre trabalho intelectual e manual, entre os que pensam e os que executam e entre os que mandam e os que cumprem ordens. Esse modelo sistêmico do planejamento, de acordo com o referido autor, diz respeito à tendência de não propor a superação do sistema em questão. $O$ autor pontua que: "propõem-se mudanças dentro do sistema, mas não do sistema" (DEMO, 1988, p. 43).

Essas funções requisitadas aos profissionais decorrem de um conjunto de novas configurações, que exige dos assistentes sociais novas formas de realizar o trabalho profissional. Para tal afirmação, considera-se que a relação estabelecida entre as mudanças contextuais verificadas no modo de organização dos mecanismos de produção e reprodução da vida social e material, nos meios de inserção do profissional no mercado de trabalho e as novas situações que emergem desse conjunto de relações, confluem para a construção de um profissional propositivo e articulado com as novas formas de organização e gestão do trabalho profissional. Também, há se se considerar indubitavelmente, o enxugamento da máquina pública, como é o caso do contingenciamento de recursos financeiros das políticas educacionais, através de novos programas do governo federal, vem apresentando novos de desafios à profissão.

Nesse sentido, para a realização do trabalho do assistente social no âmbito da gestão pública, torna-se indispensável, que a ação profissional se fundamente e um planejamento organizado, baseado nas diretrizes das políticas educacionais e diretrizes curriculares para o curso de graduação, e em conhecimento teórico-prático amplo e crítico sobre a gestão do trabalho profissional nas políticas educacionais. Que oportunamente contribuirá para direcionar a ação profissional, para além das ações antes voltadas e limitadas à execução terminal do tecnicismo e do burocratismo. 
Segundo Paiva (1999), o tema gestão e todo o seu aporte teórico-metodológico é revestido de detalhadas recomendações técnicas, em virtude de advir da área da administração, entretanto:

A conceituação de noções como eficiência, eficácia e efetividade; o detalhamento das diferentes funções gerenciais, planejamento, organização, direção e controle; a caracterização dos diferentes níveis organizacionais - estratégicos, tático, operacional - encontram na bibliografia pertinente uma série de orientações, análise e exercícios que podem ser úteis e facilitadores da organização do projeto de intervenção do assistente social, que desempenha a função de gestor na área social, dependendo do uso que se faça deles (PAIVA, 1999, p. 90).

Ademais, é importante compreender que a administração se consolida como processo intrínseco a qualquer atividade que envolva recursos, e que visa atingir algum objetivo. Desse modo, percebe-se que a administração ou a gestão consiste em uma atividade inseparável de qualquer situação que envolve pessoas, recursos e a intenção de desenvolver e realizar objetivos. Em outras palavras, o processo de tomar decisões sobre os objetivos e a utilização de recursos é entendido por administração ou gestão. Desta forma, a administração ou a gestão constitui-se de todo processo que tem a finalidade de garantir a eficiência ${ }^{3}$ e a eficácia ${ }^{4}$ de ações realizadas pelas organizações.

Importante destacar que na administração o processo administrativo compreende quatro funções básicas para que uma organização consiga a concretização de objetivos: o planejamento, a organização, a direção, o controle e avaliação.

O planejamento tem como função definir o processo e estabelecer situações futuras desejadas, além de considerar os recursos e os meios necessários para alcançar essa situação. A organização caracteriza-se como o processo de definir e detalhar o trabalho a ser realizado, as responsabilidades para a realização e distribuir os recursos disponíveis segundo critérios racionais. A função de direção visa estabelecer o processo de mobilizar e acionar os recursos, especialmente as pessoas, para concretização das atividades meio e fim. A função do controle trata-se de garantir a realização dos objetivos, bem como, identificar e apontar necessidades de mudanças. Geralmente o controle origina avaliações continuadas o que influencia diretamente no

\footnotetext{
${ }^{3}$ Saber fazer as coisas de maneira adequada, resolvendo certos problemas sem gerar aumento de custos.

${ }^{4}$ Saber fazer as coisas certas, maximizando a utilização de recursos, obtendo resultados positivos para a organização.
} 
desenvolvimento dos profissionais, das pessoas garantindo a qualidade dos resultados das ações planejadas.

Torna-se necessário, dizer que a administração é uma ciência organizada por uma série de teorias, possui um corpo sistematizado de conhecimentos, baseados em princípios e conceitos que tratam diretamente dos seres humanos. De modo que, as teorias que fundamentam a administração demonstram que as funções gerenciais podem ser desempenhadas por qualquer pessoa responsável por algum tipo de atividade organizada no âmbito organizacional.

Sob esta diretriz o assistente social demanda competências e habilidades para construir modalidades interventivas no cotidiano de trabalho. E para tal proposição, deve se apropriar de teorias que the possibilite o aperfeiçoamento do conhecimento adquirindo, voltando-se para o desenvolvimento de competências e habilidades no âmbito da gestão, enquanto instrumento de trabalho e de domínio do assistente social.

Entretanto, este processo de apropriação, perpassa pela necessária aquisição ou aperfeiçoamento de conhecimentos sobre os conceitos e princípios que fundamentam a gestão, enquanto metodologia de realização do trabalho profissional. Por isso, ressalta-se que antes de tudo é preciso competência crítica para discernir exigências burocráticas puramente executivas de funções gerenciais que são requeridas do profissional. Tendo em vista que, as particularidades que envolvem o trabalho do assistente social postulam uma postura crítica e comprometida com a consolidação dos direitos sociais e não com a execução burocrática e alienada dos serviços sociais na esfera pública.

Importante mencionar que as funções gerenciais desempenhadas pelos assistentes sociais devem estar alinhadas com os princípios e valores fixados no Projeto Ético Político Profissional (PEPP) e com as prerrogativas legais que regulamentam a profissão, objetivando assim, afastar o trabalho profissional de abordagens funcionalistas e meramente executivas, e permitir que se avance em abordagens democráticas.

\section{O Curso de Serviço Social na Universidade do Pampa}

O curso de bacharelado em Serviço Social no município de São Borja iniciou-se em 2006, e tem a duração de quatro anos, dividindo-se em oito semestres. De caráter diurno e com uma perspectiva interdisciplinar, presencial, foi o "primeiro curso de Serviço Social criado por uma Instituição Federal de Ensino Superior no Rio Grande do Sul, haja vista que o primeiro Curso em instituição privada no Rio Grande do Sul já possui mais de 50 anos" (UNIPAMPA, 2016, p. 28). Desde sua gênese, a instituição "objetiva formar profissionais capacitados para intervir nas diversas expressões da questão social, visa 
contribuir com o desenvolvimento da pesquisa e da produção intelectual relacionada ao estudo da questão social e suas múltiplas expressões na sociedade brasileira" (UNIPAMPA, 2016, p. 7).

A escolha pela cidade de São Borja deu-se a partir de um estudo onde foi possível perceber um baixo desenvolvimento econômico e social. Com isso, foi implantado o curso de Serviço Social no município por conta da "necessidade da construção de projetos locais e regionais que partissem das condições históricas do lugar, da sua cultura, dos seus recursos e da sua gente" (UNIPAMPA, 2016, p. 29) e como forma de ampliar o mercado de trabalho e o atendido às necessidades sociais, econômicas, culturais, educacionais e de saúde da população são borjense a partir da execução de políticas públicas.

O curso tem como objetivo geral "promover a educação superior de qualidade, com vistas à formação de profissionais comprometidos com desvendamento e intervenção na questão social e as suas expressões, com base nos princípios e valores defendidos pelo projeto ético político do Serviço Social" (UNIPAMPA, 2016, p. 40), para que, desta forma, os profissionais tenham a capacidade de executar as políticas públicas através de uma compreensão sensível da realidade do usuário. Situando seus objetivos específicos em:

\footnotetext{
"Preparar profissionais a partir de uma teoria social crítica, que possibilite a apreensão da totalidade social em suas dimensões de universalidade, particularidade e singularidade; Orientar profissionais comprometidos com a direção social e política do projeto profissional; Capacitar profissionais para a apreensão do significado social da profissão e para o desvendamento das possibilidades de intervenção contidas na realidade; Subsidiar profissionais com bases teóricometodológicos, ético-políticos e técnico-operativos; Formar profissionais comprometidos com os valores e princípios norteadores do Código de Ética Profissional; Instruir profissionais com clareza das competências e atribuições à apreensão e intervenção nas expressões da questão social, nos diferentes espaços sócio-ocupacionais; Proporcionar a formação de profissionais a partir da articulação entre ensino, pesquisa e extensão, fomentando problematizações acerca das particularidades da questão social na realidade regional de fronteira oeste (UNIPAMPA, 2016, p. 40)".
}

O curso busca desenvolver no profissional uma consciência não só reflexiva, mas crítica, onde o indivíduo seja capaz de intervir na vida do usuário e nas expressões da questão social a qual o mesmo se encontra, aplicando seu conhecimento teórico e executando políticas públicas, sempre comprometido com o seu Código de Ética Profissional e seu Projeto Ético Político.

A implantação do curso no campus São Borja trouxe significativas mudanças para 
a cidade e para a região, de forma que um relevante índice de discentes formados foram aprovados em concursos públicos, mestrados, doutorados, da mesma forma que ocorreu uma ampliação no mercado de trabalho, colaborando muito para a evolução do território (UNIPAMPA, 2016, p. 30). Ainda nessa perspectiva, a formação profissional deve "viabilizar a capacitação teórico-metodológica e ético-política, como requisito fundamental para a execução de atividades técnico-operativas, com vistas à apreensão crítica dos processos sociais, numa perspectiva de totalidade" (UNIPAMPA, 1999).

A partir desta breve contextualização sobre o Curso de Serviço Social, adentra-se especificamente, nas atribuições do Coordenador de Curso que estão definidas no Art. 105 do Regimento Geral da UNIPAMPA, estabelecido na Resolução CONSUNI n 5/2010 e disponível, assim como todas as demais Resoluções deste órgão, que normatizam a Instituição, na página http://porteiras.r.unipampa.edu.br/portais/consuni/resolucoes/

Art. $5^{\circ} \mathrm{A}$ Coordenação de Curso é a estrutura executiva responsável por empreender as atividades necessárias à consecução das finalidades e dos objetivos do Curso que coordena, conforme legislações pertinentes, normas institucionais e o Projeto Pedagógico do Curso (PPC). Parágrafo único. As competências da Coordenação de Curso estão descritas no Regimento Geral da UNIPAMPA, do Campus e do Curso (UNIPAMPA, 2019a, p. 2).

Destacamos a seguir as atribuições que, do ponto de vista merecem destaque (embora todas as outras tenham importância e devem ser conhecidas pelo coordenador):

Art. 105. Compete ao Coordenador de Curso executar as atividades necessárias à consecução das finalidades e objetivos do Curso que coordena, dentre elas: II. promover a implantação da proposta de Curso, [...] e uma contínua avaliação da qualidade do Curso, conjuntamente com o corpo docente e discente; III. encaminhar aos órgãos competentes, [...], as propostas de alteração curricular aprovadas pela Comissão de Curso; IV. formular diagnósticos sobre os problemas existentes no Curso e promover ações visando à sua superação; VII. servir como primeira instância de decisão em relação aos problemas administrativos e acadêmicos do Curso [...]; IX. cumprir ou promover a efetivação das decisões da Comissão de Curso; XII. relatar ao Coordenador Acadêmico as questões relativas a problemas disciplinares relacionados aos servidores e discentes que estão relacionados ao Curso que coordena; XIV. providenciar, de acordo com as orientações da Comissão de Ensino, os planos de todas as disciplinas do Curso, [...]; XV. contribuir com a Coordenação Acadêmica para o controle e registro da vida acadêmica do Curso nas suas diversas formas; XVI. orientar os alunos do Curso na matrícula e na organização e seleção de suas atividades curriculares; XXI. promover a adaptação curricular para os alunos ingressantes com transferência, aproveitamento de disciplinas, trancamentos e nos demais casos previstos na legislação; XXII. atender às demandas da Coordenação 
Acadêmica em todo o processo de colação de grau de seu curso. Os aspectos acadêmicos e pedagógicos são tratados na definição da Comissão de Curso (Art. 97), da qual o coordenador é presidente (UNIPAMPA, 2010, p. 27-28).

Textualmente, o Art. 97 nos diz que:

A Comissão de Curso é o órgão que tem por finalidade viabilizar a construção e implementação do Projeto Pedagógico de Curso, as alterações de currículo, a discussão de temas relacionados ao curso, bem como planejar, executar e avaliar as respectivas atividades acadêmicas (UNIPAMPA, 2010, p. 26).

Destaca-se que a Comissão de Curso é presidida pela Coordenadora e composta por todas/os docentes que atuam no curso, bem como pelas representações de discentes e técnico-administrativos em educação. Dessa forma, existe uma corresponsabilidade entre todos os atores que exercem papéis em um curso de graduação de levarem o projeto pedagógico desse curso adiante. Dentro da Comissão de Curso, um grupo menor de docentes possui atribuições mais específicas.

\begin{abstract}
A ideia do NDE surge da constatação de que um bom curso de graduação tem alguns membros do seu corpo docente que ajudam a construir a identidade do mesmo. Não se trata de personificar um curso, mas de reconhecer que educação se faz com pessoas e que há, em todo grupo social, um processo de liderança que está além dos cargos instituídos. Se a identidade de um curso depende dessas pessoas que são referências, tanto para os alunos como para a comunidade acadêmica em geral, é justo que se entenda e se incentive o reconhecimento delas, institucionalmente, para qualificar a concepção, a consolidação e, inclusive, a constante atualização de um projeto pedagógico de curso. Com isso se pode evitar que os PPC sejam uma peça meramente documental (UNIPAMPA, 2010, p. 11).
\end{abstract}

A normatização dos Núcleos Docentes Estruturantes pelo Ministério da Edcuação deu-se via Resolução CONAES n 1/2010. Na UNIPAMPA, a Resolução nº 97, de 19 de março de 2015, institui o Núcleo Docente Estruturante (NDE) e estabelece suas normas de funcionamento.

Outrossim, os coordenadores de curso são responsáveis ou corresponsáveis por vários processos referentes não só à condução da implantação do projeto políticopedagógico, mas também ao controle e registro acadêmico institucional. Como em geral os processos referentes aos registros acadêmicos são mais técnicos e mais dependentes de legislação e de normas internas, o coordenador segue as normativas internas já préestabelecidas para esses fluxos.

Exercer o papel da gestão significa realizar o planejamento das ações que serão 
desenvolvidas e dos objetivos que se deseja alcançar. Para a autora Baptista (2015, p. 14), "a partir da delineação é possível aprofundar-se sobre a problemática e a intencionalidade da questão, delimitar os objetivos com precisão e, dessa forma, atingir os resultados almejados no processo".

Portanto, neste intenso campo de disputas históricas sociais, estão os profissionais do Serviço Social e cada vez mais está assumindo cargos de gestão, basicamente na formulação, execução e controle da implantação da política de educação.

\section{Considerações Finais}

Mediante a breve reflexão aqui apresentada e, com o intuito de oferecer subsídios teóricos da gestão para o Serviço Social, este estudo buscou o aprofundamento teórico e a construção de conhecimento em torno da temática apresentada, bem como contribuir para o crescimento do Serviço Social, especialmente, na área de gestão e trabalho profissional.

Observou-se que o profissional se depara com dificuldade de criar, recriar e implementar propostas de trabalho condizentes com a realidade apresentada cotidianamente. Entretanto, mediante a leitura da realidade e considerando o compromisso e posicionamento ético-político da profissão em defesa dos direitos sociais e humanos, faz-se necessário à construção de planos de trabalhos concretos e coerentes que viabilize aos usuários da Política de Educação, o acesso aos direitos constitucionalmente garantidos.

Sob esta perspectiva, considerou-se que a gestão do trabalho e a capacidade de analisar, refletir, planejar e organizar a ação profissional se tornam instrumentos importantes na construção de uma prática propositiva, capaz de superar as contradições postas pelo sistema vigente e consolidar os valores e princípios fixados no projeto éticopolítico da profissão.

O profissional deve estar aberto a incorporar os princípios da gestão no cotidiano de trabalho. Visando assim, contribuir para a construção de um novo perfil profissional, capaz de responder conscientemente as demandas emergentes na sociedade, através do exercício profissional propositivo pautado em ações previamente planejada, fundada no conhecimento e domínio dos princípios de gestão, bem como sobre as dimensões teórico-prático postulados pelo Serviço Social e que fundamentam o exercício profissional.

\section{Referências}




\section{Obevisto}

BAPTISTA, Myrian Veras. (1978). Planejamento: introdução à metodologia do planejamento social. $2^{\mathrm{a}}$ edição. São Paulo, Cortez \&Moraes ltda.

BAPTISTA, Myrian Veras. (2015). Planejamento social: intencionalidade e instrumentação. São Paulo, Veras.

DEMO, Pedro. (1988). Participação é conquista. São Paulo, Cortez.

FILHO, Rodrigo de Souza. (2013). Gestão Pública \& Democracia: A Burocracia em Questão. 2.ed. Rio de Janeiro, Lumen Juris.

IAMAMOTO, Marilda Vilela. (2001). O Serviço social na Contemporaneidade: trabalho e formação profissional. 5. Ed. São Paulo, Cortez.

NOGUEIRA. A.M. 2007. Teoria da Administração para o século XXI. São Paulo, Ática Universidade.

ROSA. J.S. da. (2008). A matéria Administração e Planejamento na Matriz Curricular do curso de Serviço Social. Dissertação Mestrado em Serviço Social - Universidade Federal de Santa Catarina. Florianópolis.

PAIVA, Beatriz Augusto. (1999). Reflexões sobre pesquisa e processos de formulação e gestão.In. Capacitação em Serviço Social e Política Social: Módulo 4: O trabalho do assistente social e as Políticas Sociais. Brasília, CEAD.

UNIPAMPA. Universidade Federal do Pampa. Edital da Pró-Reitoria de Graduação (PROGRAD). (2019b). Edital n 62/2019. Bagé.

UNIPAMPA. (2016). Universidade Federal do Pampa. Projeto Pedagógico do Curso de Serviço Social - Bacharelado. São Borja.

UNIPAMPA. (2019) Universidade Federal do Pampa. Conselho Universitário da Universidade Federal do Pampa. Resolução n 253, de 12 de setembro de 2019. 


\begin{abstract}
:
The study aimed to understand the importance of the Social Worker work management process in Education Policy, more specifically in the Coordination of Social Work Course. It was questioned whether the theoretical and methodological principles of management apply in the federal public sector, where the work to be carried out already obeys a previously planned and orchestrated agenda by the federal sphere, as it obeys plans and goals established by the managing bodies of policies public. Then, it was asked whether it would be possible to build the theoreticalpractical process of management and how to carry it out in the field of professional practice, where the overvaluation of bureaucratic work directly interferes with professional action, a process that contributes to the construction of a practice emptied and uncritical professional. Also in this questioning guideline, it was also asked, what are the theoretical and practical principles of management that the social worker could appropriate as a work tool in his performance in the public sector, where the professional routinely runs into institutional limits and power relations established in the state apparatus. The documentary and bibliographic study was characterized by its exploratory character and qualitative approach. It was considered that the process of valuing bureaucratic work has been gradually encouraging the bureaucratization of practice and the professional void, a fact that conditions professional practice to bureaucratic and routine tasks. Work management and the ability to plan and organize professional action on a purposeful basis become instruments of great importance in the formulation of proposals to face the challenges posed to Social Service professionals.

KEYWORDS: Management; Planning; Education; Social Work; Work.
\end{abstract}

\section{RESUMEN:}

El estudio tuvo como objetivo comprender la importancia del proceso de gestión del trabajo del trabajador social en la Política Educativa, más específicamente en el Curso de Coordinación del Trabajo Social. Se cuestionó si los principios teóricos y metodológicos de gestión se aplican en el sector público federal, donde el trabajo a realizar ya obedece a una agenda previamente planificada y orquestada por la esfera federal, ya que obedece a los planes y objetivos establecidos por los órganos directivos de Políticas públicas. Luego, se preguntó si sería posible construir el proceso teórico-práctico de gestión y cómo llevarlo a cabo en el campo de la práctica profesional, donde la sobrevaloración del trabajo burocrático interfiere directamente con la acción profesional, un proceso que contribuye a construcción de una práctica profesional vacía y no crítica. También en esta guía de preguntas, también se preguntó cuáles son los principios teóricos y prácticos de gestión que el trabajador social podría apropiarse como herramienta de trabajo en su desempeño en el sector público, donde el profesional se topa habitualmente con límites institucionales y relaciones de poder establecidas. en el aparato del estado. El estudio documental y bibliográfico se caracterizó por su carácter exploratorio y enfoque cualitativo. Se consideró que el proceso de valoración del trabajo burocrático ha estado alentando gradualmente la burocratización de la práctica y el vacío profesional, un hecho que condiciona la práctica profesional a las tareas burocráticas y rutinarias. La gestión del trabajo y la capacidad de planificar y organizar la acción profesional con un propósito determinado se convierten en instrumentos de gran importancia en la formulación de propuestas para enfrentar los desafíos planteados a los profesionales del Trabajo Social.

PALABRAS-CLAVES: gestión; Planificación; Educación; Trabajo Social; Trabajo. 